\title{
Experimental Investigation of Impact Load Effect on the Flexural Behavior of Reactive Powder Concrete Slabs with Different Thicknesses
}

\author{
AL Zahid Ali Adnan", AL Kulabi Ahmed Kamil ${ }^{\#}$ \\ ${ }^{\#}$ Department of Civil Engineering, University of Kufa, Kufa, Najaf, 54001, Iraq \\ E-mail:alia.alzahid@uokufa.edu.iq,ahmedk.kadhim@uokufa.edu.iq
}

\begin{abstract}
Recently, buildings have been exposed to terrorist attacks that generate impact loads on their elements and affect their serviceability loads, which is the thing that inspired researchers to investigate the properties of reactive powder concrete, such as strength, serviceability loads, impact load, and the influences of impact loads on standard weight concrete separately. Therefore, the main goal of this paper is studying the flexural behavior of reactive powder concrete after applying impact load caused by the attacks. For this study, three reactive powder concrete slabs: the first one is with 80-mm thickness, the second one is with 60-mm, and the third one is with 40-mm thickness, were statically loaded after being subjected to impact load. Moreover, then a number of the three slabs' properties were investigated, such as flexural load capacity, deflection, and number and widths of cracks. The laboratory tests have approved that the slab with the higher thickness and steel fiber has improved and provided the best serviceability loads after being dynamically loaded.
\end{abstract}

Keywords — impact load; flexural capacity; steel fiber; thickness; deflection

\section{INTRODUCTION}

Reactive Powder Concrete is a new production concrete that provides following mechanical properties: high compressive strength, high splitting tensile strength, and high flexural strength when it is compared with standard weight concrete [1], [2]. These properties have attracted the attention of people working in construction media, designers and researchers, to more investigate its other properties and behavior when it is subjected into dynamically and statically loads. Many reasons have called researchers to profoundly studying RPC like it exhibits more resistance to dynamic loads applied on buildings whether created naturally and humanly [3], [4]. Earthquake and wind loads usually cause nature dynamic loads, while humanly dynamic loads are produced from human-made actions, such as vehicle bombs [5]. Hence, this study aims to investigate the influence of impact load on serviceability loads of the Reactive Powder Concrete slabs. This study also aims to provide a better explanation about the impact load decreases the flexure capacity and increases the deflection to find out the crack numbers and widths.

Consequently, this study might help architecture in structurally designing buildings in a safer way. To get these questions answered, three concrete slabs already dynamically loaded by the author AL Zahid [6] were statically loaded. The three tested slabs had the same dimensions $80 \times 80 \mathrm{~cm}$ and the same ratio of steel fiber that was $0.5 \%$ but had different thicknesses where thicknesses of the slabs were 40,60 , and $80 \mathrm{~mm}$. Therefore, one parameter, thickness, was investigated to find out the importance of the slab thickness in reducing the effect of impact loads on serviceability loads of RPC slabs.

\section{MATERIAL AND METHOD}

This section comprises a summary of all of the material properties of slabs that were defined by AL Zahid [6]. In addition, it includes the testing methods: impact and static tests.

\section{A. Material Properties of RPC Slabs}

RPC was produced by mixing the followings: cement, fine aggregate, silica fume, steel fiber, and glenium.

1) Cement: Ordinary Portland Cement was used for producing the three concrete slabs.

2) Fine Aggregate: Particles sizes of the fine aggregate ranged from $(600 \mu \mathrm{m})$ to $(150 \mu \mathrm{m})$.

3) Silica Fume: Pozzolanic material is one of the critical parameters of RPC. It works as a binder and filler in the mix. The type of silica fume used is Sika-Fume S92D. 
4) Steel Fiber: The main advantage of using steel fiber is to enhance the ductility of concrete [7]. The type of steel fiber used is WSF 0213 that is manufactured by Ganzhou Daye Metallic Fiber Co., Ltd.

5) Glenium: The used type of glenium is Glenium 54. This type of additives is a water reducer additive, and it is needed to improve the workability of Reactive Powder Concrete [8].

\section{B. Impact Test Apparatus}

The AL Zahid [6] measured the effect of impact loads manufactured impact test apparatus locally. The manufactured apparatus is illustrated in Fig. 1.

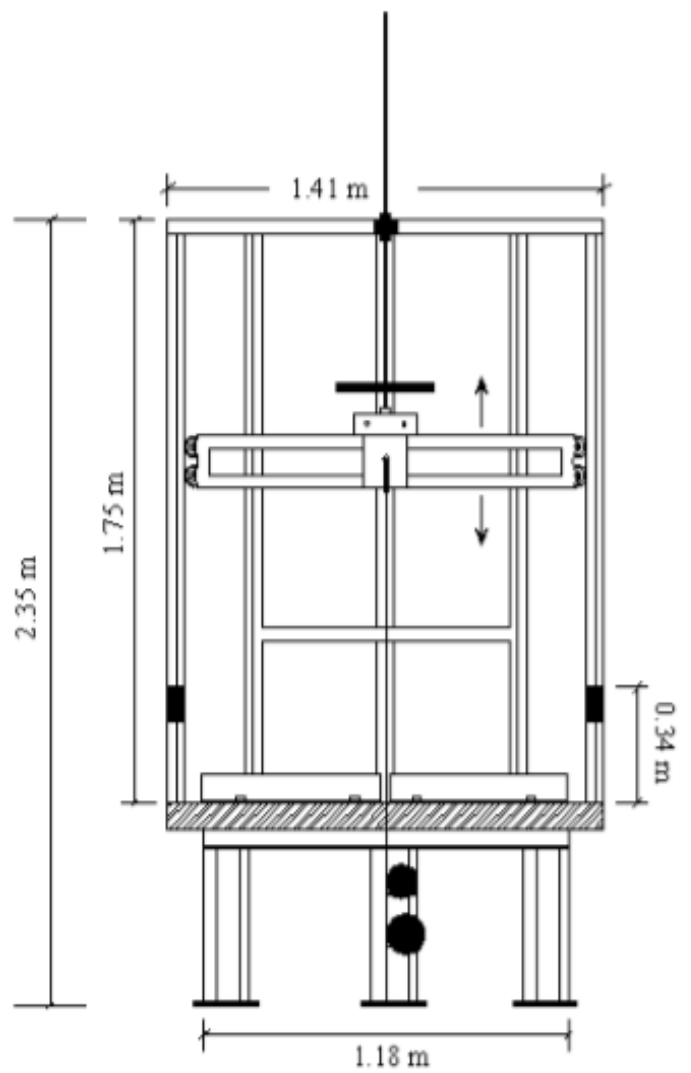

Fig. 1 Impact test apparatus

The apparatus included the following parts: an electronic accelerometer sensor, electronic infrared sensor, electronic ultrasonic sensor, and a steel ball.

The main advantage of using the electronic accelerometer sensor is to measure the impact force with time, or it measures the acceleration. Next, the electronic infrared sensor measures the mid-span displacement of slabs with time. The ultrasonic sensor measures the lateral movement of the slabs. The steel ball is a free fall mass of a $5 \mathrm{~kg}$ weight.

\section{Method of Testing the Impact Load}

After putting each slab on the apparatus, the mentioned sensors in the previous section are placed in the following situations:

- The accelerometer sensor was set to the steel on the steel ball.

- The infrared sensor was fixed at mid-span of the bottom face of the slabs.
- The ultrasonic sensor was placed in a way where it can measure the lateral displacement

The steel ball in each test was freely dropped from a 120 $\mathrm{cm}$ height to fall at mid-span of the top face of slabs. Moreover, simultaneously the sensors record and send the data to two laptops connected to them as shown in Fig. 2.

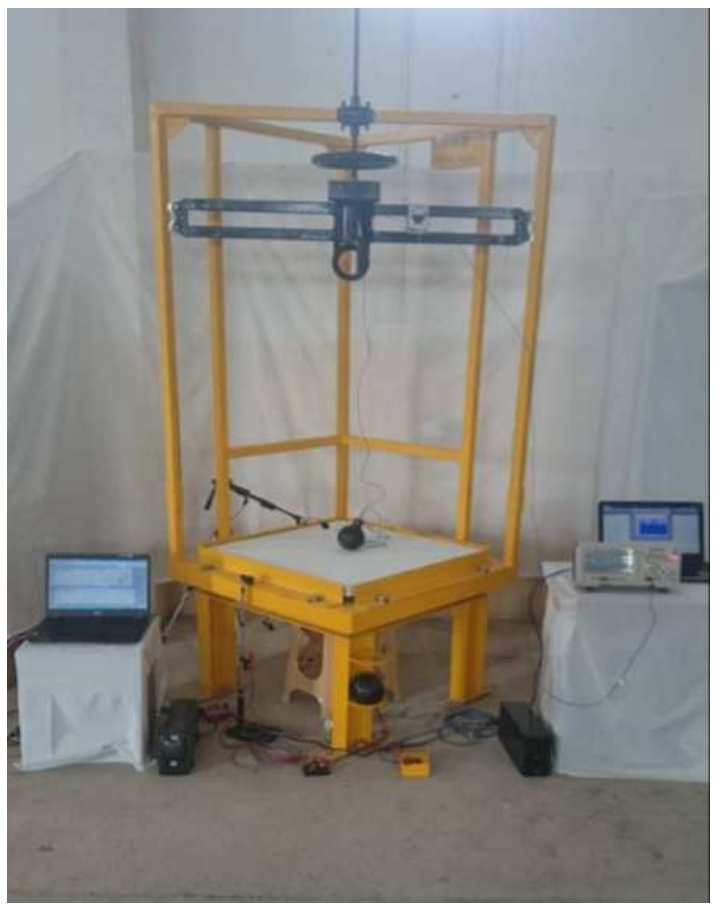

Fig. 2 Impact test apparatus with sensors

\section{Method of Testing the Static Load}

Some studies and researches were published regarding the behavior of Reactive Powder Concrete and reinforced concrete. Some of these published researches investigated the flexural behavior of RPC, for example, Aravind et al. [9] studied the flexural capacity of high strength reinforced RPC beam with $(1.5 \times 1.5 \times 0.18) \mathrm{m}$ dimensions. While the other studies researched the behavior of Reactive Powder Concrete under impact loads, for instance, Jia et al. [10] investigated the effect of blast loads on two ways reinforced concrete slabs. However, the lack of research on the behavior of RPC and reinforced concrete after being subjected to blast loads, impact loads requires to conduct an in-depth investigation and perform experimental research to figure out the behavior of RPC under static loads rather than dynamically loaded. For that purpose, the above-defined RPC slabs in the previous sections were loaded again statically.

Whereas, the slabs were set up on the flexural strengthtesting machine, and the slabs were merely supported by manufacturing a frame with a welded roller that only prevents vertical movement at supports as illustrated in Fig. 3.

The slabs were loaded through a solid square cube to achieve the condition of two-way loading slab. Besides, an electronic dial gauge was installed at the center of the bottom face of the slabs to measure the deflection of slabs to failure. 


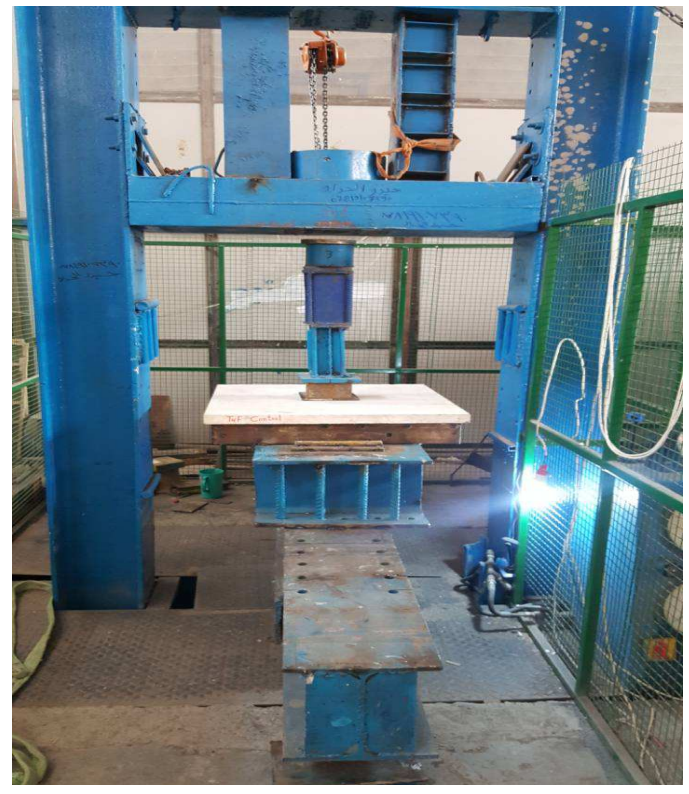

Fig. 3 Flextural strength testing apparatus

\section{RESULTS AND DISCUSSIONS}

In this section, the results of the entire compression test, dynamic test, and static test results are included. Moreover, the results discussion are comprised in this section.

\section{A. Compression Test Results}

The average compressive strength tests of three cubes of the three RPC are summarized in Table 1 as recorded by AL Zahid [6]. Besides, the table includes the age of cubes where the tests were performed for the three slabs. The RPC slab with $40 \mathrm{~mm}$ thickness is named $\mathrm{T} 4 \mathrm{~F}$, the RPC slab with $60 \mathrm{~mm}$ thickness is named T6F, and T8F refers to the RPC slab with $80 \mathrm{~mm}$ thickness.

TABLE I

Average Compressive Strength Test of Three Cubes

\begin{tabular}{|l|l|l|}
\hline Slab & Compression Strength & Age (Day) \\
\hline $\mathrm{T}_{4} \mathrm{~F}_{\text {control }}$ & 88.42 & 51 \\
\hline $\mathrm{T}_{6} \mathrm{~F}$ & 90.36 & 54 \\
\hline $\mathrm{T}_{8} \mathrm{~F}$ & 87.31 & 55 \\
\hline
\end{tabular}

Moreover, the failure shape of the compressive strength test of the RPC slabs' cubes is shown in Fig. 4.

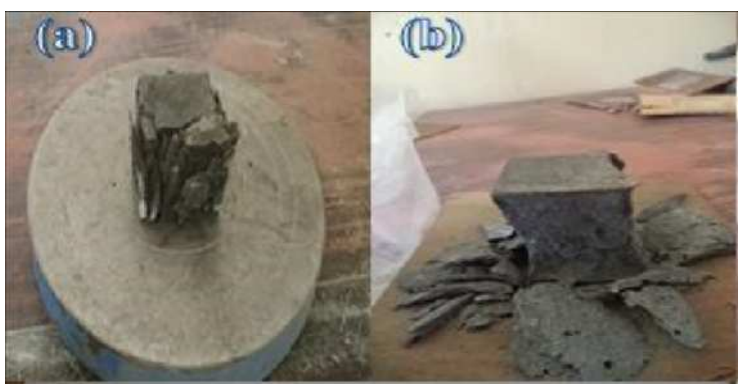

Fig. 4 Failure shape of the three RPC slabs' cubes

\section{B. Impact Load Testing Results}

The recorded data after applying the impact load on the slabs are summarized in Table 2 [6].
TABLE II

IMPACT TEST RESULTS

\begin{tabular}{|l|l|l|}
\hline Slab & Impact Load $(\mathbf{K N})$ & Deflection $(\mathbf{m m})$ \\
\hline $\mathrm{T}_{4} \mathrm{~F}_{\text {control }}$ & 5.57 & 5.085 \\
\hline $\mathrm{T}_{6} \mathrm{~F}$ & 6.56 & 3.427 \\
\hline $\mathrm{T}_{8} \mathrm{~F}$ & 6.93 & 2.347 \\
\hline
\end{tabular}

As it can be noticed, the slab with higher thickness, T8F, withstood the higher impact load $(6.93 \mathrm{KN})$ and provided the least deflection $(2.347 \mathrm{~mm})$. Moreover, the same slab, T8F, had the least crack width.

The crack widths of the slabs caused by impact loads that are included in Table 2. are comprised in Table 3.

TABLE III

AVERAGE CRACK WIDTHS OF SLABS

\begin{tabular}{|l|l|}
\hline Slab & Average Crack Width $(\mathbf{m m})$ \\
\hline $\mathrm{T}_{4} \mathrm{~F}_{\text {control }}$ & 0.0537 \\
\hline $\mathrm{T}_{6} \mathrm{~F}$ & 0.0300 \\
\hline $\mathrm{T}_{8} \mathrm{~F}$ & N/A \\
\hline
\end{tabular}

Furthermore, the crack patterns of the slabs were compared; the comparison included the crack number, crack location, and crack length. Where the slab with the least thickness, T4Fcontrol, had a higher number of cracks and the longest cracks than other slabs, and these cracks were spread out through the four quarters of the bottom face of the slab as shown in Fig. 5 [6].
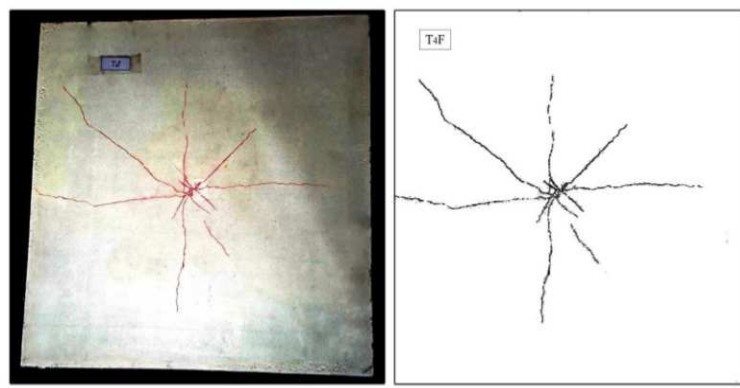

Fig. 5 Crack pattern of the slab $\mathrm{T}_{4}$ Fcontrol

Next, the slab T6F had a less number of cracks and shorter than the slab T4Fcontrol, and these cracks were spread out over three-quarters of the bottom face of the slab as shown in Fig. 6 [6].
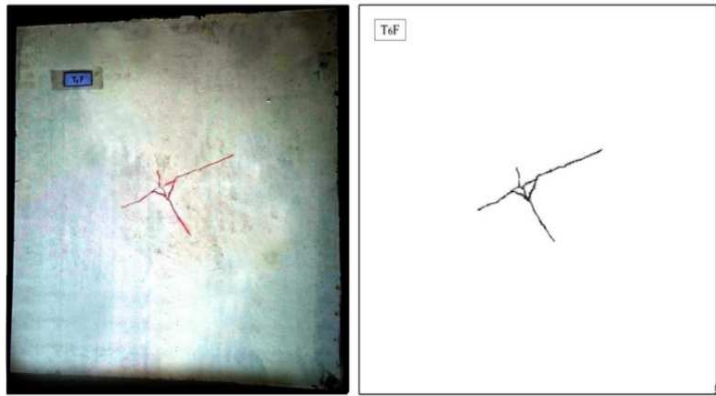

Fig. 6 Crack pattern of the slab $\mathrm{T}_{6} \mathrm{~F}$ 
While, the slab T8F, the highest slab thickness, had no visible cracks as shown in Fig. 7[6].

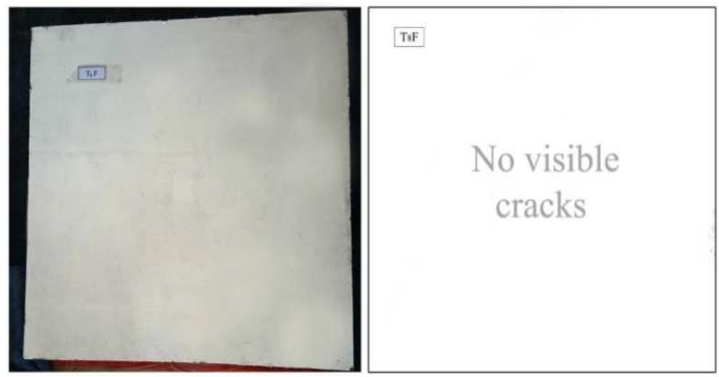

Fig. 7 Crack pattern of the slab $\mathrm{T}_{8} \mathrm{~F}$

\section{Static Load Testing Results}

The RPC slabs were loaded statically, and the corresponding deflection for each $0.5 \mathrm{KN}$ load was recorded; load increment was continued till failure for each slab. Next, the static loads and deflection of the three slabs are summarized in Table 4-A depending on the peak load of the control slab.

TABLE IV-A

FLEXTURAL TEST RESULTS

\begin{tabular}{|l|l|l|}
\hline Slab & Static Load $(\mathbf{K N})$ & Deflection $(\mathbf{m m})$ \\
\hline $\mathrm{T}_{4} \mathrm{~F}_{\text {control }}$ & 16 & 4.13 \\
\hline $\mathrm{T}_{6} \mathrm{~F}$ & 16 & 0.71 \\
\hline $\mathrm{T}_{8} \mathrm{~F}$ & 16 & 0.48 \\
\hline
\end{tabular}

And, the static peak loads and maximum deflection of the two slabs, T6F and T8F, are summarized in Table 4-B.

TABLE IV-B

FLeXTURAL TEST RESUlts

\begin{tabular}{|l|l|l|}
\hline Slab & Static Load $(\mathbf{K N})$ & Deflection $(\mathbf{m m})$ \\
\hline $\mathrm{T}_{6} \mathrm{~F}$ & 42.5 & 4.51 \\
\hline $\mathrm{T}_{8} \mathrm{~F}$ & 60.0 & 1.82 \\
\hline
\end{tabular}

As it can be noticed from the results, the slab with $40 \mathrm{~mm}$ thickness, T4Fcontrol, provided the least static load (16 KN) compared with the other slabs and second higher deflection (4.13 mm). Next, T6F slab stood a higher load than T4Fcontrol, but it deflected more, $4.51 \mathrm{~mm}$. While T8F endured the highest load $(60 \mathrm{KN})$ and deflected least $(1.82$ $\mathrm{mm})$. Load-deflection curves of the slabs $\mathrm{T}_{4} \mathrm{~F}$ control, $\mathrm{T}_{6} \mathrm{~F}$, and $\mathrm{T}_{8} \mathrm{~F}$ are illustrated in Fig. 8.

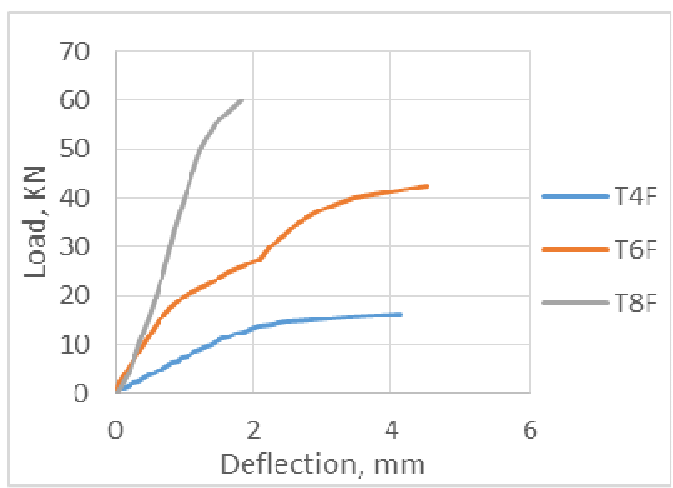

Fig. 8 Load-deflection curves of the slabs

The cracks widths and numbers of the slabs caused by the static load were monitored and compared as before for impact load. For each slab, the average of the most considerable cracks' widths was calculated and recorded. Furthermore, the first cracks, impact load cracks, were colored using a red marker, and the new cracks that are created by the static load were marked by using a blue marker to have a better idea about the increase rate in cracks' numbers and widths.

For the slab T4Fcontrol, the static load enlarged the dynamic load cracks where it is increased from $0.0537 \mathrm{~mm}$ to $0.38 \mathrm{~mm}$ and increased the rate of cracks number by about $50 \%$. The new cracks outstretched from the center of the slab throughout the dynamic loads to the edges of the slab as shown in Fig. 9.

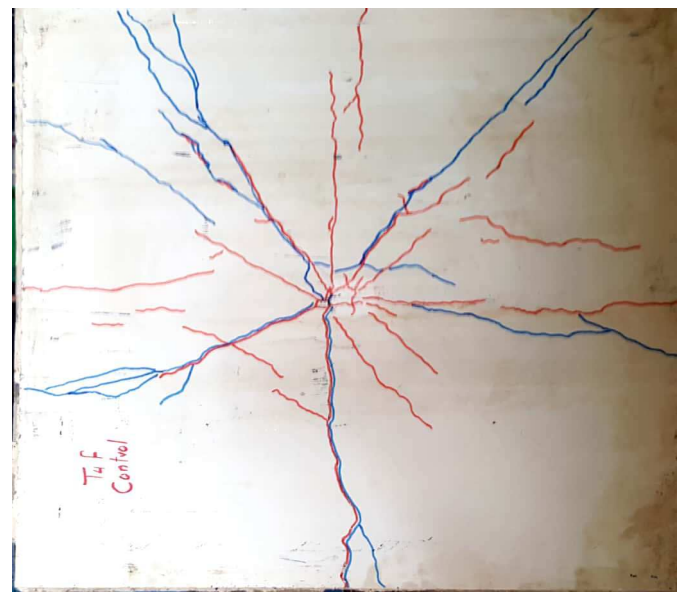

Fig. 9 Dynamic-static crack pattern of the slab T4Fcontrol

Next, the increase rate in the cracks number caused by the static load of the slab T6F is $225 \%$. Some of the new cracks extended from the slab center throughout the impact load cracks, red cracks, while the other created new paths starting from the slab center to the slab edges as illustrated in Fig. 10. Moreover, the crack width of the slab is increased from $0.0287 \mathrm{~mm}$ to $1.61 \mathrm{~mm}$.

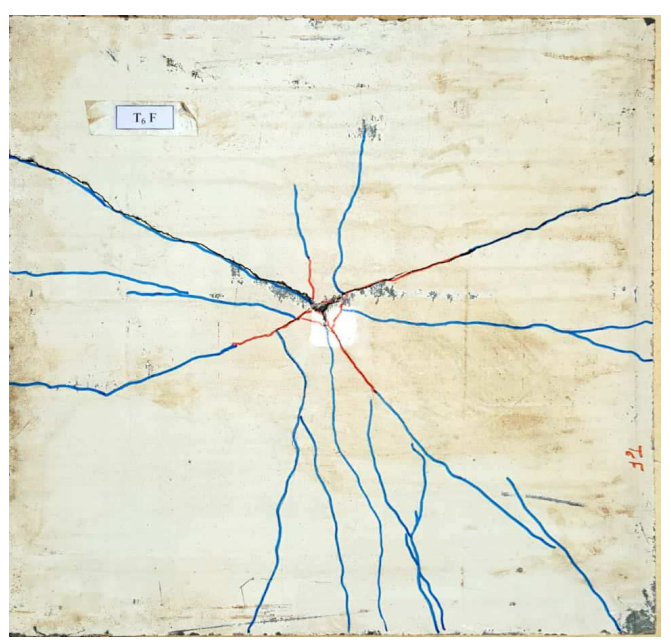

Fig. 10 Dynamic-static crack pattern of the slab T6F 
The increase rate of cracks number of the slab T8F is four times spreading out throughout the four quarters of the slab as shown in Fig. 11, and the average the crack width is increased from $0.02 \mathrm{~mm}$ to $1.01 \mathrm{~mm}$. The average cracks width of the slabs produced after applying static loads is summarized in Table 5.

TABLE V

AVERAGE STATIC CRACK WIDTHS OF SLABS

\begin{tabular}{|l|l|}
\hline Slab & Average Crack Width (mm) \\
\hline $\mathrm{T}_{4} \mathrm{~F}_{\text {control }}$ & 0.38 \\
\hline $\mathrm{T}_{6} \mathrm{~F}$ & 1.61 \\
\hline $\mathrm{T}_{8} \mathrm{~F}$ & 1.01 \\
\hline
\end{tabular}

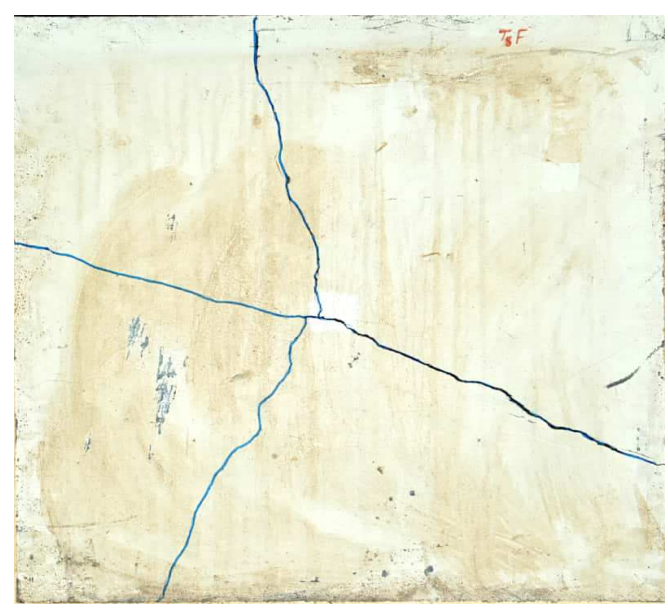

Fig. 11 The dynamic-static crack pattern of the slab T8F

\section{Results Discussion}

In this section, the results of dynamic and static tests of Reactive Powder Concrete slabs with different thicknesses having $0.5 \%$ steel fiber are discussed. In addition, some conclusions will be made based on the tests results and observations.

Needless to say that the thickness parameter is a key factor in controlling all of the resistance to dynamic loads, static loads, crack width, crack numbers, deflection, and type of failure.

Concerning loading capacity, increasing the slab thickness has improved the slab resistance to impact and static loading capacity. For example, increasing the slab thickness by $50 \%$ (40 to 60) $\mathrm{mm}$ increased the impact loading capacity by $17.8 \%$ and the static loading capacity by $165.63 \%$, and increasing the slab thickness by $100 \%$ (40 to 80 ) $\mathrm{mm}$ increased the impact loading capacity by $24.4 \%$ and the static loading capacity by $275 \%$. Fig. 12 illustrates the influence of increasing the slab thickness rate on the slabs dynamic and static peak loads. In this figure and all other following figures, the slab T4Fcontrol is taken as reference slab, and the calculations of increasing and decreasing percentages are calculated depending upon comparing the other slabs T6F and T8F with the reference slab, T4Fcontrol.

Respecting crack width, the crack width of the RPC slabs was a function of two dependents, which are slab thickness and peak loads. Via increasing slab thickness, the crack width decreases where it shows a higher roughness, and by increasing the peak load, the crack width increases, and so on. Hence, when $50 \%$ (40 to 60 ) $\mathrm{mm}$ and the slab impact peak load increase the slab thickness by $17.8 \%$, the crack width was decreased by $44.1 \%$. While, when $100 \%$ (40 to 80 ) $\mathrm{mm}$ and the slab impact peak load increase the slab thickness by $24.4 \%$, the crack width was decreased by $100 \%$. Therefore, in the second case, the cracks were not visible. Fig. 13 shows the relation among all of the slab thickness, the dynamic peak load, and cracks width.

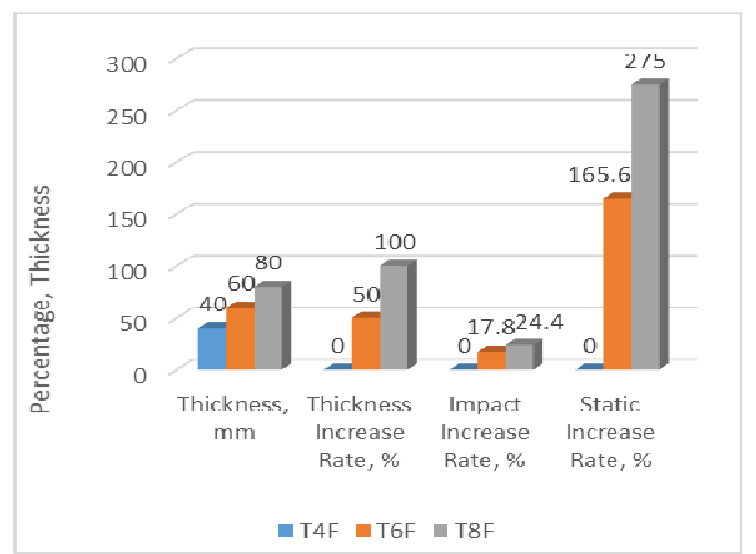

Fig. 12 Effect of thickness increase rate on the dynamic and static loading capacity of RPC slabs

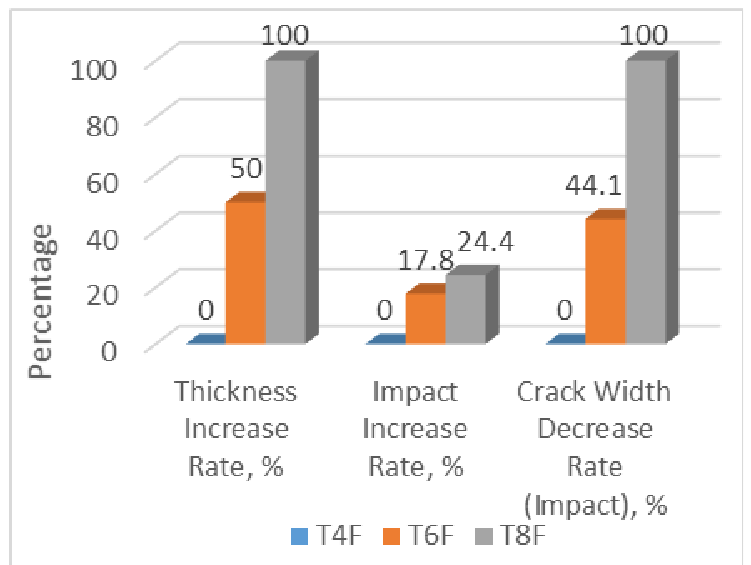

Fig. 13 The relation among the slab thickness increase rate, dynamic peak load, and crack width

After that, when the same slabs were statically loaded, the crack width increased relatively with increasing the static peak load. For example, increasing the static peak load by $165.6 \%$, the crack width increased by $323.7 \%$, and when $275 \%$ increased it, the crack width increased by $165.8 \%$. It is obvious, the increase rate of the crack width was less in the second case that is because the roughness is higher where the slab is thicker. Fig. 14. Illustrates the relation among all of the slab thickness, static peak load, and cracks width.

Regarding deflection, when RPC slabs' thickness is increased, deflection decreases when they are either dynamically or statically loaded. Where, increasing the RPC slab's thickness by $50 \%$ (40 to 60) $\mathrm{mm}$ decreased the deflection by $32.6 \%$ when it is dynamically loaded, and increasing the slab thickness by $100 \%$ (40 80) mm decreased deflection by $82.81 \%$ when it is statically loaded. Fig. 15 shows how much the RPC slabs' deflection would be 
decreased when the thickness rate is increased by the percentages mentioned previously.

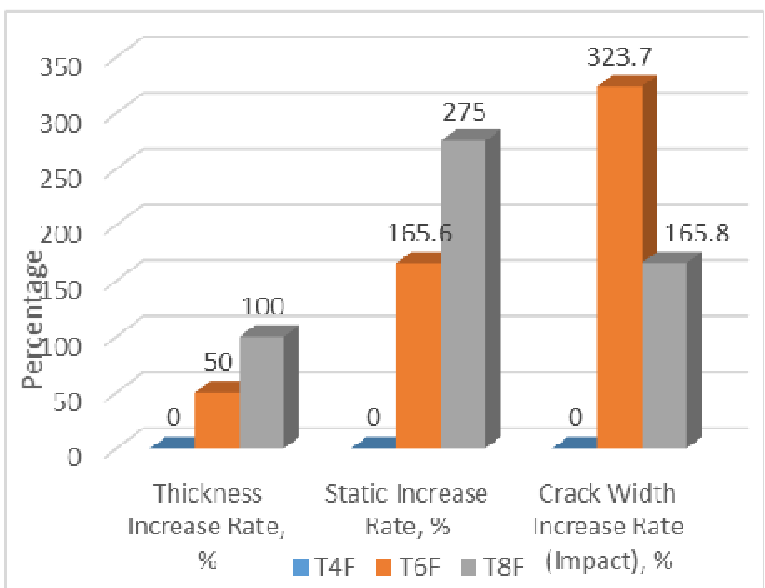

Fig. 14 The relation among the slab thickness increase rate, static peak load, and crack width

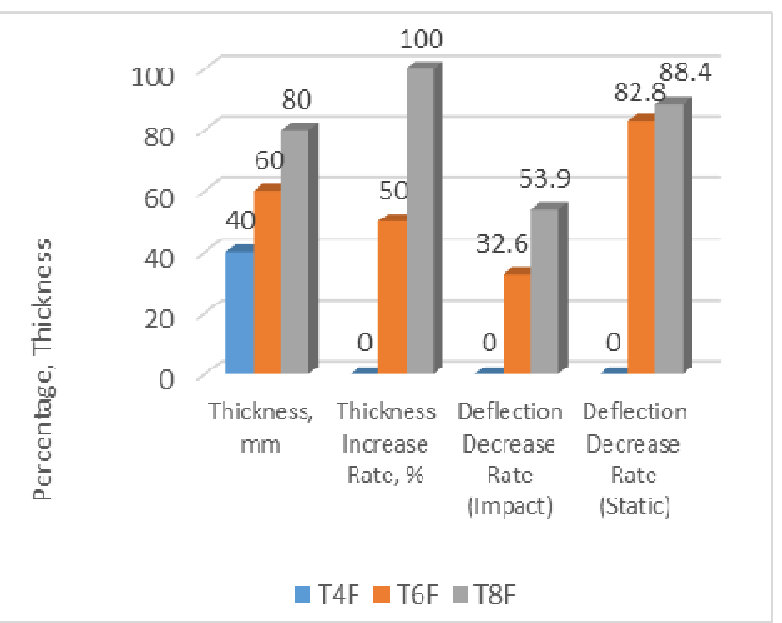

Fig. 15 Effect of thickness increase rate on the dynamic and static deflection of RPC slabs

Next thing is failure modes. Jia et al. [10] investigated the damage of two-way reinforced concrete slab caused by blast loadings. They found that the slab damage degree depends upon the weights of explosives and their positions whether they would hit the slab at center or one of its boundaries. Moreover, they specified that by increasing the explosive weights and moving toward the edges of the slab from the center, the damage degree would be increased, and the failure mode would change orderly from flexural failure into flexural-shear failure. In this study, the two variables, explosive weight, and its hitting position were not as varied as mentioned previously. Therefore, the RPC slabs have shown the same failure mode. Besides, the authors have noticed that the static failure type of RPC slabs relies mainly upon the amount of the dynamic loading and its location. Whereas the cracks of slabs after being statically loaded started from the center of the slab, which is the location of the impacting point, even though, the slabs have had different cracks density that is caused by differences in slabs thickness.
Finally, the most important result that could be discussed is the building resident's safety. Steel fiber and RPC slabs thickness are key factors in saving occupants life that could be threatened because of the collapse of buildings slabs. Whereas, steel fiber works on delaying cracks progression in slabs by increasing the ductility of concrete and consequently changing the slabs failure mode from a brittle mode into a more ductile mode [11], [12]. Afterward, the higher slabs thickness as noticed from the previous discussions, the higher dynamic and static loading capacity that could be provided. Hence, a higher roughness would be provided by increasing the slab thickness, providing more protection to buildings residents.

\section{CONCLUSION}

The percentage of subjecting buildings into blast loads and vehicle bombs is increasing. Therefore, there was a necessity to investigate the flexural loading capacity of three RPC slabs after exposing them to influence loads to get an indication about buildings slabs behavior after exposing them into dynamic loads. For that purpose, three RPC were experimentally studied; the slabs had the same ratio of steel fiber, which was $0.5 \%$ but had different thicknesses that were 40,60 , and $80 \mathrm{~mm}$. The experimental study proved that the slab with the highest thickness could provide the highest flexural loading capacity, could deflect least, could have least cracks numbers and widths and could be the safest for buildings' occupants than thinnest slabs.

\section{REFERENCES}

[1] H. A. Nuha, "Mechanical properties of reactive powder concrete (RPC) with mineral admixture," Al-Rafadain Engineering Journal, Vol. 21, pp. 92-101, 2013.

[2] W. Zemei, S. Caijun, H. Wen, and W. Linmei, "Effects of steel fiber content and shape on mechanical properties of ultra-high performance concrete," Elsevier, Vol. 103, pp. 8-14, 2016.

[3] S. Satbir, and Ritu, "Natural reactive powder concrete (RPC) - in the form of a superplasticizer portland cement mixture with silica fume, steel fibers, and ground fine quartz - a review" International Journal of Technical Research (IJTR), Vol. 5, pp. 217-222, 2016.

[4] P. B. Patel, L. S. Thakur, M. K. Maroliya, and P. A. Patel, "Shear and impact behavior of reactive powder concrete with varying powder content," Kalpa publications in CE, Vol. 1, pp. 307-314, 2017

[5] K. Zeynep, S. Fatih, and T. Necdet, "Architectural and structural design for blast resistance buildings," in The $14^{\text {th }}$ WCEE, 2008, 12-17.

[6] A. A. AL Zahid Muaid, "Impact resistance of cambered reactive powder concrete slabs with steel stiffeners," Ph.D. Eng. thesis, Babylon University, Babylon, Iraq, May 2016.

[7] A. O. Baarimah, and S. M. Syed Mohsin, "Behaviour of reinforced concrete slabs with steel fibers," in IOP, 2017, 271-012099.

[8] M. K. Maroliya, and C. D. Modhera, "Influence of type of superplasticizers on workability and compressive strength of reactive powder concrete," International Journal of Advanced Engineering Technology, Vol.I, Issue II, pp. 123-130, 2010.

[9] M. Aravind, V. Senthil Kumar, and G. Manikandan, "Flexural behavior of high strength reactive powder concrete," SSRG International Journal of Civil Engineering, pp. 350-354, 2017.

[10] J. Haokai, Y. Ling, and W. Guiying, "Damage assessment of twoway bending RC slabs subjected to blast loadings," The Scientific World Journal, Vol. 2014, pp. 1-12, 2014.

[11] P. B. Hamid, N. Behzad, and F. Majid, "Steel fiber reinforced concrete: a review," in ICSECM, 2011.

[12] A.G. Dahake, and K. S. Charkha, "Effect of steel fibers on the strength of concrete," Journal of Engineering, Science \& Management Education, Vol-9 (I), pp. 45-51, 2016. 